\title{
Pedro de la Torre y Francisco Bautista. Presencia del retablo madrileño en Castilla y León
}

\author{
Pedro de la Torre and Francisco Bautista. \\ Presence of the madrilenian altarpieces in Castile \\ and Leon
}

\author{
Juan María CRUZ Y ÁB AR \\ Museo Arqueológico Nacional
}

Recibido: 15-V-2014 / Aceptado: 7-VII-2014

Resumen: Pedro de la Torre y el jesuita Francisco Bautista crearon una red de maestros vinculados a ellos en Castilla y León. Las relaciones con José de Arroyo y Juan de Medina Argüelles, así como las obras que les dieron origen, los retablos de la Fuencisla y Santa María de Tordesillas, eran conocidas, aunque no con profundidad. En este trabajo nos proponemos dar una visión completa de la cuestión, añadiendo otros nombres (Cristóbal Ruiz de Andino, los Vélez de Margotedo o Juan Fernández) y nuevos frutos de esta colaboración, como el retablo de Santa Cruz en Medina de Rioseco (parcial), Nuestra Señora de Soterraña en Ávila y la Clerecía en Salamanca.

Palabras clave: Retablos, Siglo XVII, Castilla y León, Pedro de la Torre, Francisco Bautista.

ABSTRACT: Pedro de la Torre and the jesuit Francisco Bautista created a masters' chain linked to them in Castile and Leon. The contacts with José de Arroyo and Juan de Medina Argüelles, the works which initiated them as well, the Fuencisla and Santa María of Tordesilla's altarpieces, were known but not in depth. In this survey we are providing a complete view of the matter, also we add another names (Cristóbal Ruiz de Andino, los Vélez de Margotedo o Juan Fernández) and new results of this collaboration, the altarpieces of the Holy Cross in Medina de Rioseco (partial), Our Lady of Soterraña in Ávila and the Clerecía in Salamanca.

Key words: Altarpieces, 17th Century, Castile and Leon, Pedro de la Torre, Francisco Bautista.

La actividad dedicada a los retablos de los maestros arquitectos de la Corte Pedro de la Torre y el jesuita Francisco Bautista tuvo una influencia decisiva en Castilla y León, dejando atrás el dominio ejercido en el primer tercio del siglo XVII desde Valladolid por Gregorio Fernández y los ensambladores asociados a él, como los Velázquez. Explicaremos la repercusión de su estilo en este territorio de forma cronológica, aunque tratando de agrupar también las obras según sus ubicaciones, tarea no siempre fácil debido a la variedad de su localización. 


\section{PRIMEROS TANTEOS DE PEDRO DE LA TORRE}

Precisamente un año antes del fallecimiento de Gregorio Fernández se conoce una fugaz aparición de Pedro de la Torre en Salamanca para hacer una tasación. Se trataba del desaparecido retablo mayor de la parroquial de San Martín, trazado en 1621 por el maestro mayor de las obras reales Juan Gómez de Mora y realizado por Antonio González Ramiro' ${ }^{1}$. Terminado el retablo en 1635, Ramiro llamó a tasar a Torre, quien trajo consigo a Alonso García Becerro, que vivía en Toledo. Por la parte del comitente actuaron dos escultores salmantinos. Este dato apoya la hipótesis de que la compañía entre González Ramiro, Torre y el arquitecto de Madrid Bernabé Cordero, que se sabe que existía en 1636, pueda anticiparse un año al menos. El maestro de Salamanca salió en 1637 de la asociación ${ }^{2}$, y sería mucho tiempo después cuando resonaron allí los ecos de Pedro de la Torre: en 1665 se exigía que en el retablo de la Concepción de la catedral se tomaran como modelo las columnas salomónicas de su retablo del hospital madrileño del Buen Suceso o las del convento salmantino de San Andrés de Carmelitas calzados ${ }^{3}$.

En tierras abulenses se registra otra esporádica aparición de Pedro de la Torre.

${ }^{1}$ A. RODRÍGUEZ G. DE CEBALLOS y A. CASASECA CASASECA, "Antonio y Andrés de Paz y la escultura de la primera mitad del siglo XVII en Salamanca", Boletín del Seminario de Estudios de Arte y Arqueología, XLV, 1979, pp. 387-416; las noticias en torno a este retablo y su tasación en pp. 395-397.

${ }^{2}$ Le sustituyó el arquitecto avecindado en Madrid Juan Bautista Garrido (M. AGULLÓ Y COBO, “Pedro, José, Francisco y Jusepe de la Torre, arquitectos de retablos", Anales del Instituto de Estudios Madrileños, XXXVII, 1997, pp. 25-70, especialmente pp. 30-31).

${ }^{3}$ A. RODRÍGUEZ G. DE CEBALLOS, Estudios del Barroco salmantino: el Colegio Real de la Compañia de Jesús (1617-1779), Salamanca, 1969 (3ª ed. 2005), p. 91. En el nuevo contrato de compañía de 1637 se indicó que el objetivo fundamental de los tres maestros cortesanos era el retablo mayor del convento del Carmen calzado. Tal vez pretendiera Torre obtener este retablo madrileño a través del salmantino.
Mazón descubrió un pago de 1643 al escultor Manuel Pereira por el retablo de Marcos García, racionero de la catedral de Toledo y cantor de Felipe IV en su capilla de la iglesia parroquial de Martín Muñoz de las Posadas ${ }^{4}$. Agulló dio a conocer otras dos escrituras de ese año otorgadas por el portugués en relación con el retablo y su imagen de talla, San $\operatorname{Marcos}^{5}$. La última era un poder a Torre y Juan Bautista Garrido para cobrar de Marcos García. No se conoce ningún otro retablo contratado por Pereira. Aunque aquí aparece como contratista, esta condición no hace razonable atribuirle la traza, y menos aún cuando los dos arquitectos reciben el mencionado poder para cobrar. Las arquitecturas en madera se construían en este momento con modelos proporcionados por ensambladores especializados que los realizaban en sus amplios obradores. El estilo del retablo de Marcos García coincide con el de Pedro de la Torre, pues la cornisa que desde el frente se retrasa en forma quebrada siguiendo las columnas aparecerá después en el retablo de Orgaz ${ }^{6}$, o el atribuido de la capilla del Sagrario-Cámara Santa de la catedral de Oviedo 7 . El tipo de racimos decorados con frutos y querubines cayendo junto a los machones se hallará en el retablo de la Fuencisla que trazó dos años más tarde. No obstante, no es posible descartar plenamente a Garrido, cuyo estilo no se conoce porque no se ha conservado ninguna de las obras que se hizo por su invención.

Pereira era colaborador y gran amigo de Garrido, y éste a su vez tenía compañía

${ }^{4}$ M. A. MAZÓN DE LA TORRE, Jusepe Leonardo y su tiempo, Zaragoza, 1977, pp. 106-107.

${ }^{5}$ M. AGULlÓ Y COBO, "Manuel Pereira: Aportación documental", Boletín del Seminario de Estudios de Arte y Arqueología, XLIV, 1978, pp. 257-278, p. 260.

${ }^{6}$ Documentado por J. NICOLAU CASTRO, “El desaparecido retablo de la parroquial de la villa de Orgaz y sus pinturas de Francisco Rizi", en In sapientia libertas: escritos en homenaje al profesor Alfonso E. Pérez Sánchez, Madrid, 2007, pp. 471-474.

${ }^{7}$ J. M. CRUZ YÁBAR, "Pedro de la Torre y Francisco Bautista en el norte de España", Anales del Instituto de Estudios Madrileños, LI, 2011, pp. 101-116, pp. 108-109. 
con Torre desde 1637, lo que explica la presencia de los tres en esta obra. Su precio, relativamente alto -27.000 reales-, lo percibió Pereira como contratista e incluiría la arquitectura, talla, escultura, dorado y pintura. Sabemos con certeza que los dos arquitectos llevaron 6.900 reales de los últimos 12.150 reales que Marcos García adeudaba al escultor $^{8}$, pero no sabemos si cobraron algo más en los 14.850 reales restantes. Sin duda les corresponde la arquitectura -no el pedestal, que haría un cantero- y también los marcos para nueve pinturas exentas que se situaban en las paredes interiores y exteriores de la capilla con asuntos relacionados con supuestas devociones del comitente: al exterior se sitúan el Rey David y Santa Cecilia relacionadas con su condición de cantor, además de los Evangelistas y la Concepción, y al interior San Antonio de Padua y San Francisco. El programa iconográfico hace referencia a San Marcos, titular de la capilla por el nombre del comitente, que escribe mirando a Cristo y aparece nuevamente entre los Evangelistas, que repiten la postura en relación con la Concepción, a la que cantan alabanzas David y Cecilia. Deben de ser de mano de Pereira San Marcos, el león, la peana y un par de ángeles en el remate. Nada se sabe del dorado y estofado de la madera e imágenes, ni del autor de las pinturas del banco (Salvador, San Pedro y San Pablo) y ático (Cristo de la paciencia), y de los nueve lienzos citados. El pintor Luis Fernández era habitual colaborador de Pereira y Garrido, al igual que Jusepe Leonardo, pero preferimos atribuirlas al primero, ya que el segundo estaba en ese tiempo ocupado en obras para el Rey.

El 1 de junio de 1651 se obligaron Pedro de la Torre y su mujer Francisca de Castro a realizar el sepulcro de mármol de San

\footnotetext{
${ }^{8}$ El pago parcial del 19 de junio fue de 6.403 reales y tres cuartillos; se deduce que hubo un pago anterior de 8.447 reales.

${ }_{9}$ Parte de la obra la harían Diego Folco y Diego Antúnez, colaboradores portugueses de Pereira, testigos en uno de los pagos.
}

Pablo de don Antonio de Camporredondo y Río, santiaguista, miembro del Consejo real y presidente del de Hacienda, en la capilla del convento del Carmen descalzo en Valladolid, de la que era patrón ${ }^{10}$. La traza por la que se había de hacer quedó firmada de las partes y el escribano, pero las armas estaban ya fabricadas y sólo había de asentarlas. Camporredondo concretaría si el letrero en piedra blanca con sus guardas o fajas de mármol de San Pablo alrededor se había de hacer en alabastro o en piedra de Tamajón. De esta última piedra serían el bulto y sitial y de la que pareciera más conveniente los adornos de los lados que iban sobre el cuadro y también el festón con el resalto de donde colgaría éste. El sepulcro debía de tener 164 pies superficiales, concertado a ocho ducados el pie, 14.432 reales en total, y el bulto y sitial 6.300. Además cobraría 3.000 más por llevar la piedra labrada de Madrid a Valladolid y asentarla con el escudo de armas, pero si el comitente decidiera llevar a su costa la piedra, Torre percibiría solo 2.000 reales por el asiento ${ }^{11}$. Como sucedía en Salamanca, la influencia no es inmediata ni derivada de esta obra y hay que llegar a 1657 para que se perciba la estela de Pedro de la Torre en la ciudad del Pisuerga. En ese año se exigía a Cristóbal Ruiz de Andino ${ }^{12}$, que las columnas salomónicas del retablo del hospital de la Pasión trazado por él fueran como las del Buen Suceso.

${ }^{10}$ J. L. BARRIO MOYA, "Sobre una obra desaparecida de Pedro de la Torre en Valladolid", Boletín del Seminario de Estudios de Arte y Arqueología, IL, 1983, pp. 484-486.

11 Se habían adelantado 6.600 reales, y se darían 4.400 para San Miguel, 6.212 a fin de diciembre (1.000 menos si el transporte fuera por cuenta del presidente) y los 4.400 reales últimos al acabar, que debía ser para fin de mayo de 1652. Los cónyuges hipotecaron su casa llamada de las Siete Chimeneas en la calle de la Libertad, y ese mismo día se obligó el caballero de Santiago, quien conocía bien a Torre por estar haciendo el retablo mayor de la parroquia real de Santiago en Madrid, que él administraba para Felipe IV.

${ }^{12}$ J. J. MARTÍN GONZÁLEZ, Escultura barroca castellana, t. I, Madrid, 1958, p. 58. 


\section{LA CONSOLIDACIÓN DE AMBOS MAESTROS: SEGOVIA Y TORDESI- LLAS}

Será a partir de 1651 cuando los modelos de Pedro de la Torre y Francisco Bautista se extiendan por las tierras leonesas y castellanas. Ambos habían viajado seis años antes a Segovia a llevar la traza para el retablo de la ermita de la Virgen de la Fuencisla (Fig. 1), que sería la obra determinante de esta influencia ${ }^{13}$. Tovar afirmó que Bautista se desvinculó de la materialización del retablo, pues no seguía su estilo ${ }^{14}$. En cuanto a su desvinculación, haremos notar -lo que no se ha observado hasta ahora- que Bautista se limitaba a trazar y no participaba en la construcción del retablo cuando eran encargos ajenos a su congregación. Pero no es exacto que la Fuencisla no muestre rasgos suyos.

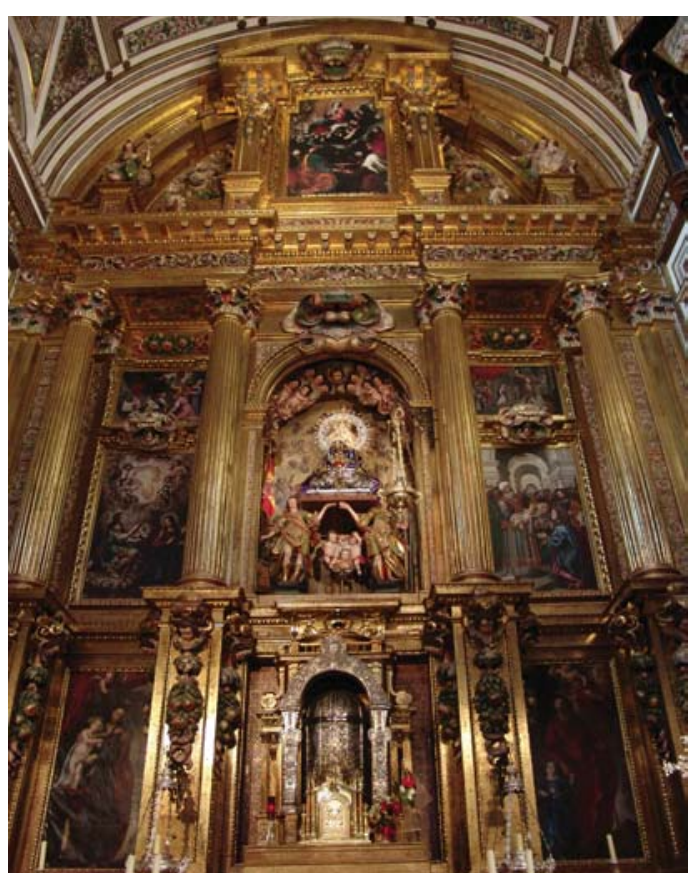

- Fig. 1. Pedro de la Torre (traza y realización) y Francisco Bautista (traza). Segovia, ermita de la Virgen de la Fuencisla. Retablo mayor. Foto del autor

${ }^{13}$ Cobraron por ella 800 reales. A. MARCOS, "El retablo mayor del santuario de la Fuencisla. Su arquitecto, escultor, doradores, estofadores y pintores", Estudios Segovianos, 2-3, 1949, pp. 251-254.

${ }^{14} \mathrm{~V}$. TOVAR MARTÍN, Arquitectos madrileños de la segunda mitad del siglo XVII, Madrid, 1975, p. 195.
Fue Pedro de la Torre quien concertó en 1651 con el licenciado Mateo Rodrigo Frechel, administrador de la ermita y santuario, la hechura del retablo conforme a la traza que para ello tenían hecha, firmada de ambos y del escribano. Acudieron con las condiciones al doctor don Juan de Paredes, consultor de la Inquisición y provisor y vicario general de la ciudad y su obispado para que diera licencia. La petición de Frechel decía que se trató de hacer el retablo en tiempo del obispo don Pedro de Neyla (1645-1648) con Pedro de la Torre, "maestro mayor de architectura", para cuyo efecto se le pidió que hiciese una traza, "la mejor que se pudiese ymaxinar". La hizo y gustó mucho al obispo, pero falleció cuando trataba de comenzarse. Le sucedió fray Francisco de Araujo (16481656), quien ordenó al administrador que fuera disponiendo el asunto y el 18 de julio de 1651 aprobó el provisor el concierto y las condiciones.

Ese mismo día se celebró el contrato, quedando la traza, que incluía planta y alzado, en poder del administrador en la ermita. Las condiciones, fechadas el día anterior, establecían que se ajustaría el retablo con el testero y se ejecutaría la traza "con la mayor perfección que oy se ace en España, obserbando en todo la buena architectura con todos los requisitos que muestra el diseño echo por Pedro de la Torre"15. Completado

\footnotetext{
${ }^{15}$ Archivo Histórico de Protocolos de Segovia, Protocolo 1.260, fol. 437-445v. La ermita debía costear las cajas o fosas que se abrieran en la pared $u$ otra cosa que tocase a albañilería y poner la madera nueva en el obrador, como la de los andamios, que daría armados. En cambio sería a cargo de Torre el transporte y asiento de la talla y escultura que se labrara en Madrid, y también la reparación si algo se quebrara. De cada paga debía dejar en poder del administrador el coste de los oficiales que trabajasen en Segovia, y lo restante se destinaría a lo que se hiciera en Madrid. Cada dos meses visitarían la obra Pedro de la Torre o su hijo Juan, bajo pena de 20 ducados. Si por algún accidente o duda del aparejador de la obra tuviera que venir personalmente, avisado por certificación de la estafeta, lo haría en plazo de ocho a quince días, y si no cesarían los oficiales de Segovia, siendo los daños por su cuenta, y por la ermita si no diera el administrador el dinero semanal que constaba en una lista.
} 
el primer tercio del retablo mandaría lo que le correspondiera de talla y escultura antes de empezar el segundo. Lo daría terminado en tres años por 6.500 ducados $^{16}$, y por armar el retablo se le daría de ayuda de costa 500 reales, lo que hace un total de 72.000 reales. Se añadió en el concierto que enviaría las herramientas y que si incumplía, podría buscar la ermita en esos reinos y sus confines maestros que lo acabaran, "por ser obra tan grande". Debía trabajar sin alzar la mano y a satisfacción de peritos, nombrados por cada parte el suyo. Dio por fiador al dorador de Madrid Pedro Martín de Ledesma, que hipotecaba sus casas, de acuerdo con el poder que le había dado en Madrid el 11 de julio, y a Juan de la Torre, su hijo arquitecto, que estaba presente. El administrador fue fiado por Francisco Gutiérrez de la Cotera, maestro mayor y aparejador de las obras reales de Segovia, y Francisco de Castrejón.

Pedro de la Torre contó en Segovia con José de Arroyo como aparejador y responsable del ensamblaje $\mathrm{e}^{17}$, trabajando oficiales como Juan de Quintos y seguramente José Ferreras y José Vallejo Vivanco, que expandieron luego el estilo de Torre en la zona segoviana. La escultura quedó para José Ratés, incluida la talla del retablo y del transparente, instalándose en Segovia. Es posible que Ledesma, fiador pero también colaborador habitual y cuñado de Torre, dirigiera el dorado y estofado hasta que murió y lo acabaran Martín de Ortega y Pedro de Prádena $^{18}$. Dos de las pinturas son de Francisco Camilo. En 1662 se acabó la obra inaugurándose con grandes fastos.

${ }^{16} 1.500$ de contado, en nueve meses 1.200 , otros tantos en otro plazo igual, y en otro más 1.300; al final de los tres años otros 1.300 .

${ }^{17}$ Posiblemente fue maestro de José de Arroyo Juan Bautista Garrido, pues en el testamento de éste de 1644 aparece como testigo y se le denomina oficial. La amistad de Garrido con Pedro de la Torre, también testigo, explica que Arroyo trabajara para él después de esta fecha. El testamento fue transcrito parcialmente por M. AGULLÓ Y COBO, Documentos sobre escultores, entalladores y ensambladores de los siglos XVI al XVIII, Valladolid, 1978, p. 74.

${ }^{18}$ A. MARCOS, Op. cit.
Aunque el diseño muestra abundantes rasgos de Pedro de la Torre, los hay también de Bautista y su retablo mayor del Colegio Imperial jesuita de Madrid. De éste deriva el orden monumental del cuerpo central, aunque el banco sea bastante grande, las desarrolladas orejetas del ático que luego adoptará Torre en el retablo de Santa María de Tordesillas y los pedestales de los ángeles en el cuerpo superior, que repiten la disposición de los Santos Pedro y Pablo en el magno retablo madrileño. Los arbotantes en forma de voluta siguen los de la fachada del Gesú de Vignola. Los hay en la custodia, como los vemos también en la de plata de la catedral segoviana trazada por el jesuita en 1656, y en las enjutas del retablo, mayores que las tímidas insinuaciones de Torre en Martín Muñoz de las Posadas. El tarjetón sobre el arco de la Virgen es similar al de la custodia catedralicia, pero no los numerosos frutos, más del gusto de Torre que de la austeridad decorativa de Bautista, como sabemos por su dibujo, que sirvió para el retablo de Santa María de Azcoitia y de la Virgen de la Antigua en Orduña ${ }^{19}$.

El resto de la decoración es invención de Pedro de la Torre: la gloria de ángeles era habitual en los retablos, presente ya en el retablo de Begoña (1640) y seguramente en el contemporáneo de Tolosa, pero no tan movida, y los racimos frondosos de los pedestales inferiores, con cabezas de querubines y trapos como las guirnaldas sobre las pinturas de las entrecalles ${ }^{20}$. Los frutos que caen

${ }^{19}$ J. M. CRUZ YÁBAR, Op. cit., pp. 109-112. En este texto se hacen algunas propuestas para el destino original de esta traza, pero ahora, teniendo en cuenta el pitipié, que muestra cerca de $20 \mathrm{~m}$ de altura por más de 11 de anchura, parecen más adecuadas otras, como acaso las parroquias de San Juan de Urda o de Albacete. Vid. también en relación con el dibujo, F. R. BARTOLOMÉ GARCÍA y J. ZORROZUA SANTISTEBAN, "Antonio de Alloytiz y los retablos mayores de La Antigua de Orduña (Vizcaya) y Santa María de Azkoitia (Guipúzcoa). Una traza del hermano Bautista", en Scripta Varia in honorem $M^{a}$ Concepción García Gaínza, Pamplona, 2011, pp. 142-149, especialmente pp. 144-146.

${ }^{20}$ Pese a estar presentes en los colaterales del Colegio Imperial de Bautista, posiblemente sean posteriores 
sobre los arbotantes en la parte superior están ya presentes en Martín Muñoz, aunque son un elemento típico entonces en el retablo madrileño. Las tarjetas entre los lienzos encajadas con dificultad y con ayuda de una tabla reaparecen luego en Tordesillas, como los codillos de este primer cuerpo y el pabellón de la Virgen -ahora desaparecido- o el frontón sostenido por pilastras en vez de los machones del Colegio Imperial. Torre no quiso prescindir aquí ni en Tordesillas del ortodoxo capitel. El camarín era obligado por la antigüedad de la imagen de la Virgen y Torre tenía, como es sabido, sobrada experiencia en esta cuestión. El orden corintio estaba también predispuesto por la advocación mariana del templo.

Al tiempo que se empezaba este importante retablo en Segovia, la catedral hacía las primeras gestiones para relevantes obras de platería, principalmente la custodia de asiento de plata. Consta que se había presentado una traza el 12 de agosto de 1648, aunque la noticia no precisa su autor. La catedral debía estar por entonces escasa de recursos, pues se limitó a encargar una custodia portátil, de bronce dorado, al platero de Madrid Rafael González, contratada el 3 de julio de 1651. La completó satisfactoriamente, porque el 23 de junio de 1653 se pensó ya en hacer la de asiento y el 4 de julio se votó hacerla, a la par que la silla de la Virgen de la Paz del altar mayor. Se contrató con González y Juan de Vergara Costilla ante escribano el 21 de agosto de 1654 en Madrid, aunque el 28 de enero de 1655 se apartó Vergara por escritura hecha en Segovia, donde aparece como testigo José de Arroyo, citado como escultor ${ }^{21}$. El cabildo, después de comenzada la custodia de asiento, tuvo dudas acerca de la traza de González, y en la sesión de 21 de enero de 1656 se alude a la cuestión proponiendo que se enviara a Madrid porque parecía "cosa hordinaria".

al retablo segoviano.

${ }^{21}$ H. SANZ Y SANZ, "La custodia de la Catedral de Segovia", Estudios Segovianos, 62-63, 1969, pp. 341-352. Contrataron también la silla de plata de Nuestra Señora de la Paz, situada en el altar mayor, donde se conserva.
Una vez acabada, el 9 de diciembre, se propuso en cabildo que se diera un parecer por plateros madrileños, para saber si González había cumplido, pero desistieron pensando que declararían a su favor. Se optó entonces por escribir al padre provincial de la Compañía de Jesús para que por medio del padre Diego de Paniagua hicieran venir al hermano Bautista, que había hecho los diseños ${ }^{22}$. La traza puede datarse, por tanto, a comienzos de febrero de 1656. Esta intervención del jesuita en una obra arquitectónica de plata no se ha tenido en cuenta por los estudiosos del retablo ${ }^{23}$. Quizá el cabildo hubiera tenido presente a Bautista por consejo de José de Arroyo, cuya posible intervención en la obra de la custodia segoviana no se conocía.

$\mathrm{Al}$ analizar esta obra hemos de tener en cuenta que el platero ya debía tener algo avanzada la custodia cuando se produjo la intervención del hermano Bautista, pues la inscripción aclara que la empezó Rafael González el 20 de septiembre de 1653 y la acabó el 26 de abril de $1657^{24}$. El jesuita partía, por tanto, de un pie forzado. Su estilo es menos perceptible en el primer cuerpo, donde hay detalles que no aparecen en ninguna otra obra suya, como el tercio tallado de las columnas inferiores y los festones en el friso segundo, elementos ya pasados de moda a estas alturas del siglo para los arquitectos más

${ }^{22}$ Los datos fueron dados a conocer por E. ARNÁEZ, Orfebrería religiosa en la provincia de Segovia hasta 1700, Madrid, 1983, t. II, pp. 208-214, pero sin orden cronológico y sin conocer los del contrato, lo que hizo que no pudiera discernir si se referían a la custodia portátil o a la de asiento, y el estilo de ésta lo puso extrañamente en relación con Enrique de Arfe (1475-1545) en vez de con otras obras de Bautista o González.

${ }^{23}$ En los siglos XVII y XVIII fue habitual que piezas de platería de carácter arquitectónico fueran trazadas por los más famosos arquitectos de retablos, en compañía o no de los plateros, por su estructura derivada del retablo y su capacidad para decorar de manera novedosa estas piezas. Su estudio resulta imprescindible para entender la obra de estos maestros del retablo.

${ }^{24}$ J. M. CRUZ VALDOVINOS, "Platería", en Historia de las Artes Aplicadas e Industriales en España, Madrid, 1982, pp. 65-158, p. 115. Señaló la autoría de González en las dos custodias, peana y naveta. 
avanzados $^{25}$. Pero el modelo en general responde a sus postulados. Los arbotantes con volutas son los de la Fuencisla, la linterna con pilastras reaparecerá en Azcoitia, son típicos suyos los jarrones y las bolas con agujas es un recurso arcaico que va a mantener. Es novedad que las tarjetas remonten el entablamento, y no habíamos visto en su haber columnas con fustes recorridos por un emparrado que sugiere el efecto de las salomónicas, aunque estos entorchados vegetales habían sido utilizados antes por Bernabé Cordero en sus obras de Guipúzcoa, por lo que se habrían hecho en Madrid antes de $1640^{26}$.

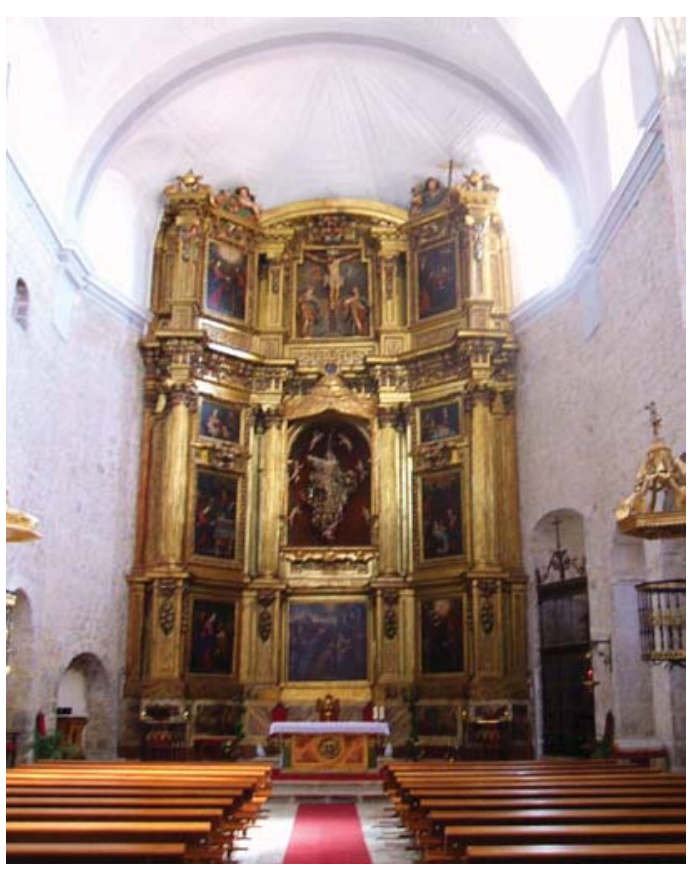

- Fig. 2. Pedro de la Torre (traza y realización). Tordesillas, iglesia parroquial de Santa María. Retablo mayor. Foto del autor

${ }^{25}$ En el concierto se estableció que la obra estaba enriquecida al estilo de platería según la dicha traza. La peana está hecha según su inscripción en 1656, y repite el estilo de la custodia de asiento, por lo que será traza de Bautista igualmente. Sería para la custodia portátil por tener el mismo material.

${ }^{26}$ Esta custodia segoviana con su tracería en tambor y cúpula y columnas pseudosalomónicas influyó directamente en la de madera que hizo Vallejo Vivanco para el altar mayor de la Compañía en la misma ciudad antes de 1678, en que concertó el retablo. Ocupa todo la calle central del cuerpo principal como hacían Bautista y otros maestros de la Compañía.
En 1655 se produjo un nuevo hito para Pedro de la Torre, esta vez con el retablo de Santa María de Tordesillas (Fig. 2), adonde debió llegar la fama del retablo de la Fuencisla que se estaba haciendo. Desde que se documentara su autoría se ha escrito mucho por su influencia en Castilla pero también en Navarra $^{27}$. El 21 de abril lo concertaron Pedro "maestro arquitecto de obras de su Magestad" y su hijo don Juan de la Torre, de más de 25 años y fuera del dominio paterno, con el licenciado Diego Fernández Castillo, mayordomo del templo, el doctor José Álvarez y el licenciado Juan Maestro, beneficiados de preste del mismo, tras haber pedido licencia al obispo de Valladolid fray Juan Merinero. La traza, hecha y firmada de las partes, quedó en poder del doctor Álvarez. La madera sería de Valsaín o de Soria. El retablo quedaría ajustado a la cabecera de tres ochavos en ancho y alto, y si hubiera que quitar una o más gradas para dejarle sitio, lo haría la iglesia. Se obligaron a hacerlo en blanco y la talla y escultura se labrarían en Madrid. La parroquia daría las nueve pinturas de Fiestas de la Virgen y el Calvario y solo tendrían que hacer los tableros embarrotados y embisagrados para defenderlas de las humedades y otros peligros habituales. Asentarían antes de dorar a vista de maestros peritos desapasionados nombrados por cada parte. El plazo eran tres años, y en cada uno de ellos debía acudir Pedro de la Torre por lo menos una vez para comprobar la buena marcha de la obra, pasando como mínimo cuatro meses entre una y otra visita, con pena de $100 \mathrm{du}$ cados en caso contrario. Asistiría a lo que se fuera preguntando en término de seis días, y en caso de accidente o fallecimiento le sustituiría su hijo. Torre cobraría 6.500 ducados, y él o José de Arroyo, aparejador mayor de la obra, darían recibos simples. Arroyo recibiría cada semana 250 reales siempre que trabajaran cada día cuatro oficiales, y 500 reales

${ }^{27}$ J. MARTÍ Y MONSÓ, Estudios histórico-artísticos, Valladolid, 1901, p. 441. Una transcripción más amplia la hizo E. GARCÍA CHICO, Documentos para el estudio del arte en Castilla. T. II, Escultores, Valladolid, 1941, pp. 312-315. 
para poder trasladar su casa a Tordesillas, pues se debía dar una para el obrador y oficiales. El contratista hipotecó una vez más su casa madrileña ${ }^{28}$.

Dos días después otorgaron padre e hijo carta de pago de 9.000 reales para comprar madera ${ }^{29}$, y el 28 de julio concertó Arroyo con dos portugueses que la serraran $^{30}$. El 13 de mayo de 1656 escribió Pedro de la Torre una carta a José Álvarez en que preguntaba por el estado de la obra, para comprobar las afirmaciones de su subordinado de que todo marchaba correctamente. Ofrecía su ayuda para conseguir más madera, que no había podido tener Arroyo, y su presencia en Tordesillas cuando hiciera falta $^{31}$. Pronto faltó dinero y la parroquia obtuvo licencia del Arzobispado para tomar un censo de 1.000 ducados el 24 de junio de 1657 y otro por igual cantidad el 4 de febrero del año siguiente ${ }^{32}$. La obra pudo avanzar y el 9 de marzo de 1658 se concertó con el arquitecto Antonio Carasa la hechura del pedestal de piedra por 1.500 reales $^{33}$; en julio quedó asentado el primer cuerpo del retablo.

De la imaginería está documentada sólo la imagen titular de la Asunción, con trono y ángeles, costeada por una particular de Tordesillas, Isabel del Campo. La hizo Alonso de Rozas, escultor de Valladolid, por 1.650 reales, por contrato de 10 de febrero de $1660^{34}$. Urrea atribuyó a raíz de esta noticia el

\footnotetext{
${ }^{28}$ Los términos contractuales son muy similares a
} los de la Fuencisla.

${ }^{29}$ J. URREA FERNÁNDEZ, "Los autores del retablo de Santa María de Tordesillas. Nuevos datos", Boletín del Seminario de Estudios de Arte y Arqueología, LIV, 1988, p. 437.

${ }^{30}$ E. GARCÍA CHICO, Op. cit., p. 315.

${ }^{31}$ Ibídem.

32 J. M. PARRADO DEL OLMO, "Nuevos datos sobre el retablo mayor de Santa María de Tordesillas", Boletín del Seminario de Estudios de Arte y Arqueología, XLVIII, 1982, pp. 435-436.

\footnotetext{
${ }^{33}$ Ibídem, p. 436.

${ }^{34}$ Ibídem.
}

Calvario del remate al propio Rozas ${ }^{35}$. Otra carta descubierta por este autor da cuenta del artífice de las dos Virtudes, Fe y Esperanza, del ático. Está fechada el 2 de mayo de 1663 y en ella advertía el arquitecto Juan de Medina Argüelles a José Álvarez que el portador de la misma, Andrés de Oliveros, iba a tomar las medidas in situ y hacer los modelos, para lo cual se le debían dar 500 reales y otros 500 al asentar. Llevaba asimismo un diseño que envió Pedro de la Torre ${ }^{36}$. Urrea adjudicó las pinturas del retablo a Felipe Gil de Mena, pintor también vallisoletano ${ }^{37}$, donadas por devotos de Tordesillas. El dorado lo concertó Pedro de Guillerón, dorador de Valladolid, el 8 de marzo de 1667 por 36.000 reales $^{38}$.

Las consideraciones estilísticas que hemos hecho en relación con el retablo de la Fuencisla son válidas para éste, pues se trata de un modelo similar, con algunas variantes, al margen de la imaginería: la planta ochavada en vez de recta, la presencia de una pintura en la parte central del banco, falta de festones rematando las entrecalles y del tarjetón de la calle central, dobles modillones en el friso y no solamente roleos, y los lienzos y soportes laterales del ático en lugar de enjutas con arbotantes.

INFLUJOS A TRAVÉS DE ARROYO Y MEDINA ARGÜELLES, COLABORADORES DE TORRE

A raíz de las construcciones de los retablos de Segovia y Tordesillas, José de Arroyo contrató obras por su cuenta en estas localidades y otras cercanas. Comenzó, como es natural, por la zona segoviana, con el retablo mayor de la parroquial de la Magdalena en el arrabal segoviano de Zamarrama-

\footnotetext{
${ }^{35}$ J. URREA FERNÁNDEZ, Op. cit., p. 437.

${ }^{36}$ Oliveros otorgó carta de pago tres días después, como consta en el reverso de la misiva. Ibídem, pp. 438439 .

${ }^{37}$ Ibídem, pp. 437-438.

${ }^{38}$ J. MARTÍ Y MONSÓ, Op. cit., p. 441.
} 
la $(1653)^{39}$, y ya en 1654 el de la cofradía de Nuestra Señora de la Soledad de Villacastín y su imagen titular ${ }^{40}$. $\mathrm{Al}$ año siguiente recibió un aprendiz en Segovia hijo de un vecino de la Corte ${ }^{41}$ y el encargo de Tordesillas. En 1656 concertó junto con el escultor Francisco Díez de Tudanca, colaborador suyo, el retablo mayor de la parroquial de Ataquines ${ }^{42}$. Tudanca no hizo nada en dos años de su profusa labor en la imaginería por estar muy ocupado, y Arroyo asumió el total de la obra ${ }^{43}$. Al quedar parada mandó de Ataquines a Segovia a dos ensambladores navarros, José de Huici e Ituren ${ }^{44}$ y Pedro Garzarón para realizar el retablo de la parroquial de Santa Eulalia de esta ciudad, que había contratado en 1657, dejándoles sus herramientas con las que habían estado trabajando en Ataquines ${ }^{45}$. Ese año se hizo cargo también del retablo de la cofradía de Nuestra Señora del Rosario, colateral de la epístola de la parroquial de Ma-

${ }^{39}$ M. T. GONZÁLEZ ALARCÓN, Retablos barrocos en el arcedianato de Segovia, Segovia, 1999, pp. 118-119. Lo dio a hacer a Miguel de Prado pero no cumplió Arroyo con su obligación.

${ }^{40}$ Ibídem, pp. 121-122. Está hoy en la ermita del Santo Cristo del Valle.

${ }^{41}$ Ibídem, p. 59.

${ }^{42}$ E. GARCÍA CHICO, Op. cit., p. 298. J. M. PARRADO DEL OLMO, "Precisiones sobre el ensamblador José de Arroyo", Boletín del Seminario de Estudios de Arte y Arqueología, LIV, 1988, pp. 431-436, p. 431.

${ }^{43}$ E. GARCÍA CHICO, Catálogo monumental de la provincia de Valladolid, T. IV, Valladolid, 1964, p. 44. M. A. FERNÁNDEZ DEL HOYO, "El escultor vallisoletano Francisco Díez de Tudanca (1616-?)", Boletín del Seminario de Estudios de Arte y Arqueología, L, 1984, p. 379.

${ }^{44}$ J. M. CRUZ YÁBAR, Op. cit, pp. 108-109. El 26 de enero de 1678 se encontraba de nuevo en Madrid, deducimos que a las órdenes del arquitecto Juan González en el retablo de Santa Juana de la Cruz en el convento de Santa María de la Cruz en Cubas de la Sagra, porque, aunque no se ha advertido, firmó como testigo en una escritura de concordia otorgada por González y José Ratés publicada por M. del SALTILLO, "Los Churrigueras. Datos y noticias inéditas (1679-1727)", Arte Español, XVI, 1945, pp. 83-106, concretamente pp. 83-84. 434.

${ }^{45}$ J. M. PARRADO DEL OLMO, “Precisiones...", p, tilla de los Caños (Valladolid) ${ }^{46}$, y del mayor de la parroquial de San Antolín de Tordesillas. Parrado del Olmo señaló la presencia de Juan de Medina Argüelles como testigo en el contrato de este último y dedujo que se había formado en el obrador de Arroyo ${ }^{47}$. Concertó éste en 1658 el retablo mayor de la parroquial de San Miguel en Pozal de Gallinas, estando en Medina del Campo aunque avecindado en Tordesillas, donde se haría el retablo ${ }^{48}$. En 1659 se hizo con el retablo de la ermita de Nuestra Señora del Carrascal en Villacastín ${ }^{49}$. Por un poder de ese mismo año dado a su mujer María de Paris, de 24 de abril, conocemos que había pactado hacer el de la parroquial de Nava de la Asunción ${ }^{50}$.

Arroyo siguió el estilo de Pedro de la Torre, visible en los retablos conservados de la Magdalena, la Soledad, San Miguel, Santa Eulalia y San Antolín, estos dos más avanzados, con los arbotantes del ático de la Fuencisla $^{51}$, el entablamento retranqueado de Orgaz y dobles modillones del friso como en Santa María de Tordesillas ${ }^{52}$. La talla era aún discreta al modo de Pedro de la Torre en los cuarenta, y de ella se ocupó Arroyo, dando a hacer a otros maestros de provincias el más sencillo ensamblaje, por no estar acostumbrados a las novedades de la Corte.

${ }^{46}$ Ibídem. Citado previamente por V. TOVAR MARTíN, Op.cit., pp. 337-338.

${ }^{47}$ J. M. PARRADO DEL OLMO, "Precisiones...", pp. 431-435. Se le dio en parte de pago por éste el nicho y custodia que había anteriormente en el presbiterio, que vendió Arroyo a la parroquia de San Juan de la localidad, recibiendo pagos de 1658 a 1661.

${ }^{48}$ E. GARCÍA CHICO, Catálogo monumental..., pp. 64 y 66 .

${ }^{49}$ M. T. GONZÁLEZ ALARCÓN, Retablos barrocos en el arcedianato de Segovia, Madrid, 1995, p. 126.

${ }^{50}$ J. M. PARRADO DEL OLMO, “Precisiones...”, p. 435. Parece que lo llegó a hacer porque quedan restos de un retablo en la iglesia que han de ser de éste por estilo: lienzos con marcos de codillos y tarjetas de las entrecalles, pilastras, semicolumnas y enjutas.

${ }^{51}$ Ausentes en el retablo de Segovia.

${ }^{52}$ Estos rasgos no están presentes en Zamarramala ni Villacastín. 
Para Arroyo trabajó Huici, y una vez que acabó su labor en Segovia ${ }^{53}$, fue a Ovie$\mathrm{do}^{54}$. Ignacio de Cajigal, maestro mayor y tracista de la capilla del Sagrario-Cámara Santa o las Reliquias en la Catedral ovetense, le trajo de ahín ${ }^{55}$. Supusimos que podía haber hecho obras anteriormente para el obispo Bernardo Caballero de Paredes, promotor de la capilla, por ejemplo en su fundación del convento de agustinas recoletas de Medina del Campo. Precisamente el 1 de septiembre de 1658, cuando contrató Arroyo el retablo de Pozal de Gallinas, se declaró estante en Medina del Campo ${ }^{56}$. Así entraría en contacto con Cajigal, quien le requeriría una traza para Oviedo de Pedro de la Torre y Bautista, y encontrarían a Huici dispuesto para la hechura, pues en el norte no habría quien pudiera materializar esas novedades sin dirección ${ }^{57}$.

En tierras navarras existe otro retablo de 1663 que sigue con bastante fidelidad el modelo de Tordesillas, el de la parroquial de Santa María de Viana. Fue trazado en ese año por el arquitecto de Arnuero (Cantabria)

${ }^{53}$ Tenía que acabar para el 15 de agosto de 1658 en Santa Eulalia de Segovia. Es posible que aún hicieran Huici y Garzarón un pequeño retablo ahí que Parrado atribuyó a Arroyo, y para éste en 1659 el de Nava de Coca o de la Asunción, en Segovia. Estaría en Oviedo antes del 25 de octubre de 1660, cuando se contrató el retablo.

${ }^{54}$ J. M. CRUZ YÁBAR, Op. cit., pp. 107-109. Hacemos en este apartado mención de algunas obras y autores ajenos en parte a la zona de estudio del artículo, Castilla y León, por ser imprescindibles para nuestra explicación de la influencia en ella de Torre y Bautista.

${ }^{55}$ G. RAMALLO ASENSIO, "Intercambio artístico Asturias-Navarra. El navarro José de Huici Eiturren, sus actividades en la catedral de Oviedo y sus relaciones profesionales con Luis Fernández de la Vega", en Scripta Varia in honorem $M^{a}$ Concepción García Gaínza, Pamplona, 2011, pp. 666-673, p. 669.

${ }^{56}$ Tal vez sea suya la custodia del altar mayor de las monjas.

${ }^{57}$ Tras trazar también el monumento de Semana Santa de la Catedral, Huici volvió a Navarra para hacer desde 1663 el retablo de Santiago en Puente la Reina, reutilizando la traza de Pedro de la Torre para Tordesillas (vid. nota 53).
Pedro de Margotedo. Sería padre de Diego Vélez de Margotedo, quien el 1 de septiembre de 1664 contrató el retablo desaparecido de la Virgen del Dado en la catedral de León, declarando ser vecino de Oviedo. En 1666 aparece en León José de Margotedo, probablemente hermano de Diego, que siguió esquemas de Pedro de la Torre en sus retablos. También hizo labor en Madrid un dorador de nombre Cosme Vélez de Margotedo, que debió aprender ahí como ya señalamos en caso de los ensambladores montañeses Fernando de la Peña y Juan Antonio del Casti$10^{58}$. Es probable que los Vélez de Margotedo trabajaran en el retablo y monumento de Semana Santa ovetenses, lo que explica su relación indirecta con Pedro de la Torre y Bautista a través de Huici.

No conocemos la conexión entre el retablo de Oviedo y el mayor del relicario de la colegiata jesuita de Villagarcía de Campos (Valladolid), cuya semejanza fue advertida por Ramallo. Realizado por Cristóbal Ruiz de Andino y trazado por Lucas González, de Medina de Rioseco, no hay que descartar que pudiera haber sabido éste de la obra asturiana a través de alguno de sus artífices, incluidos los Margotedo de León. Las similitudes son múltiples, hasta el punto de ocupar todo el nicho del primer cuerpo una custodia como en Oviedo, rasgo caracterizador de Bautista ${ }^{59}$, o el entablamento quebrado de Torre. La factura es, no obstante, menos avanzada que la de estos maestros.

Al ser de Medina de Rioseco, González pudo saber también de este retablo por Medina Argüelles, estrechamente relacionado con Madrid. Tras fallecer el aparejador de Pedro de la Torre, José de Arroyo, con el que hacía el retablo de Santa María de Tordesillas, Medina ocupó su lugar, recibien-

\footnotetext{
${ }^{58}$ Eran hijos de los socios Alonso de la Peña y Juan del Castillo, tasadores en 1663 de la capilla de la Cámara Santa de Cajigal, y realizadores del retablo. El pedestal de éste lo haría Cajigal.

${ }^{59}$ Incluso rematan ambos con una talla de la Inmaculada Concepción.
} 
do de aquél antes del 2 de mayo en 1663 la traza para las dos esculturas de remate. El 15 de julio de ese año contrató el retablo de la parroquial de Santa Cruz de Medina de Rioseco ${ }^{60}$, según su traza, de la que se había pedido previamente opinión a maestros de la Corte, sin duda por su iniciativa. Pérez de Castro, que publicó la noticia ${ }^{61}$, supuso que uno de ellos pudo ser Pedro de la Torre, en lo que no tenemos ninguna duda por la coincidencia de fechas de ambos requerimientos a Madrid, que serían simultáneos por parte de Argüelles $^{62}$. Años después, en 1672, se pudo repetir la intervención con los Torres cuando se enviaron trazas desde Madrid para las puertas y canceles para el mismo templo; también se citan unos diseños ${ }^{63}$ que se suponían de Medina Argüelles, pero serían de los madrileños, por ser el único en contacto con ellos entre los maestros que concurrieron a esta obra.

Ahora bien, si para las puertas y canceles hicieron falta trazas de los Torres que se atribuyeron a Medina Argüelles, cabe preguntarse si no pasó otro tanto nueve años antes para el retablo. Se enviaron diseños que se devolverían modificados total o parcialmente. En el concierto de Medina se señala: "para lo qual hiço traça con las condiciones de lo que se a de obrar" y en las condiciones, firmadas por este maestro, se establecieron algunas que indican que, efectivamente, se utilizó la nueva traza con los cambios: "Es condición que a plomo de los pedestales lleva sus columnas salomónicas, que aunque no están en la traza las lleba dicha obra conforme una que tengo echa". Y "teniendo en cuenta las condiciones antecedentes, es condición que las colunas de la custodia an de ser salomóni-

${ }^{60}$ E. GARCÍA CHICO, Catálogo monumental de la provincia de Valladolid, t. I, Valladolid, 1956, pp. 132-134.

${ }^{61}$ R. PÉREZ DE CASTRO, “Actividad artística y talleres de ensamblaje en Medina de Rioseco (1650-1675). Lucas González", Boletín del Seminario de Estudios de Arte y Arqueología, LXVI, 2000, pp. 269-290, p. 273.

${ }^{62}$ Otros podrían ser Francisco de la Torre, su sobrino y colaborador habitual, y el propio Francisco Bautista.

${ }^{63}$ Ibídem, p. 286. cas sin envargo de lo que estava pactado por otras de las condiciones antecedentes".

El retablo de Medina de Rioseco es muy peculiar por la manera en que soluciona el problema de su verticalidad. Si analizamos como la resolvió Medina Argüelles tres años más tarde en Cigales, observaremos -como hizo Martín González ${ }^{64}$ - que sigue la estructura de Santa María de Tordesillas. En cambio la de Medina de Rioseco responde a un tipo característico de Pedro y José de la Torre que no podía conocer Medina Argüelles. Es un desarrollo del retablo de Tordesillas y otros anteriores, como la capilla de Gonzalo Hurtado en el convento de la Trinidad calzada de Toledo (contratado por Pedro en 1652) ${ }^{65}$, o el de Fuente el Saz (de José, anterior a 1655) ${ }^{66}$. Consiste en la entrada de la imagen central del cuerpo principal en el siguiente rompiendo el entablamento, algo no novedoso, pero sí que se acompañe de calles laterales prolongadas en los cuerpos superiores, creando aparentemente un cuerpo más que el habitual banco, cuerpo principal y ático. La culminación del esquema sería este retablo riosecano, que supone la repetición de Fuente el Saz, pero en planta recta, no ochavada. Con él se buscaría dar relevancia a la advocación del templo. Los restantes rasgos pudieron ser perfectamente propuestos por Medina Argüelles, puesto que derivan todos de la Fuencisla (reflejado en los retablos de Arroyo) y Tordesillas, por lo que es posible que la modificación de Madrid se refiriera solamente a la calle central, y que no especificara la decoración del fuste de las columnas, que Argüelles hizo salomónicas según su primera propuesta.

${ }^{64}$ J. J. MARTÍN GONZÁLEZ, El retablo barroco en España, Madrid, 1993, p. 100.

${ }^{65}$ A. J. DÍAZ FERNÁNDEZ, "El arquitecto madrileño Pedro de la Torre en Toledo y un retablo inédito localizado", Espacio, Tiempo y Forma, Serie VII, Nueva época 1, 2013 (en prensa).

${ }^{66}$ J. L. BARRIO MOYA, “José de la Torre y Francisco Ricci, autores del retablo mayor de la iglesia de Fuente el Saz del Jarama", Anales Complutenses, XII, 2000, pp. 43-54. 
En el retablo mayor de Santa María del Azogue de Urueña (Valladolid) utilizó Medina otra vez el diseño de Tordesillas ${ }^{67}$, como ocurrió en el de Cevico de la Torre (Palencia), realizado por Cristóbal Ruiz de Andino y Villota. Éste confirma que Andino conocía muy bien la obra de Pedro de la Torre, como ya vimos con ocasión del hospital vallisoletano de la Pasión; es posible que trabajara para Arroyo en Santa María de Tordesillas. Precisamente las columnas del hospital del Buen Suceso fueron mencionadas en otro retablo palentino, éste trazado por Medina Argüelles y destinado a la capilla de la Cruz en la Catedral. En 1679 pujó por él con los palentinos Juan y Mateo Sedano. Las condiciones se han citado habitualmente por dos de sus cláusulas referidas a Pedro de la Torre, en que se le denomina el más grande escultor de España para justificar que las columnas salomónicas se hicieran de cinco vueltas como en el Buen Suceso, pero se han puesto en boca de los Sedano. En realidad fueron redactadas por Medina Argüelles, quien hizo la alusión, casi a modo de homenaje, al fallecido maestro cortesano ${ }^{68}$.

\section{EL GRAN FINAL: BAUTISTA EN ÁVI- LA Y SALAMANCA}

Si la influencia de éste se extendió desde Segovia al norte hasta Tordesillas y más allá, la de Francisco Bautista lo hizo hacia el oeste hasta Salamanca. El 6 de abril de 1672 hizo escritura en Madrid el ensamblador José de Acedo para realizar el retablo de Nuestra Señora de la Soterraña en la ciudad de Ávila como se había convenido con don Sebastián de Briviesca, secretario real, conforme a la planta que estaba hecha y quedaba en poder de Acedo, a satisfacción de Francisco Bautista. La tarea incluía, además de la madera, su dorado y estofado y los pedesta-

${ }^{67}$ E. GARCÍA CHICO, Documentos..., pp. 321-322. Si bien solo se conserva el primer cuerpo, es suficiente para revelar el parentesco.

${ }^{68}$ Acababa de finalizar Medina Argüelles el retablo de otra capilla catedralicia, el de San Fernando. les que estaban al lado del altar, fingidos de mármol y jaspe como mostraba la traza, y el marco del frontal. Acabaría el 8 de agosto y cobraría 8.000 reales, 3.000 de contado, otros tantos para fin de mayo y los 2.000 últimos al acabar y asentar la obra, para lo cual le daría el secretario cabalgadura ${ }^{69}$. No hay duda de que éste había acudido al jesuita para obtener el proyecto y para que le recomendara quien le diera forma satisfactoriamente. La Virgen de Soterraña, patrona de Ávila ${ }^{70}$, estaba ubicada desde el siglo XIII en la cripta de la iglesia de San Vicente, y de ahí proviene su nombre ${ }^{71}$.

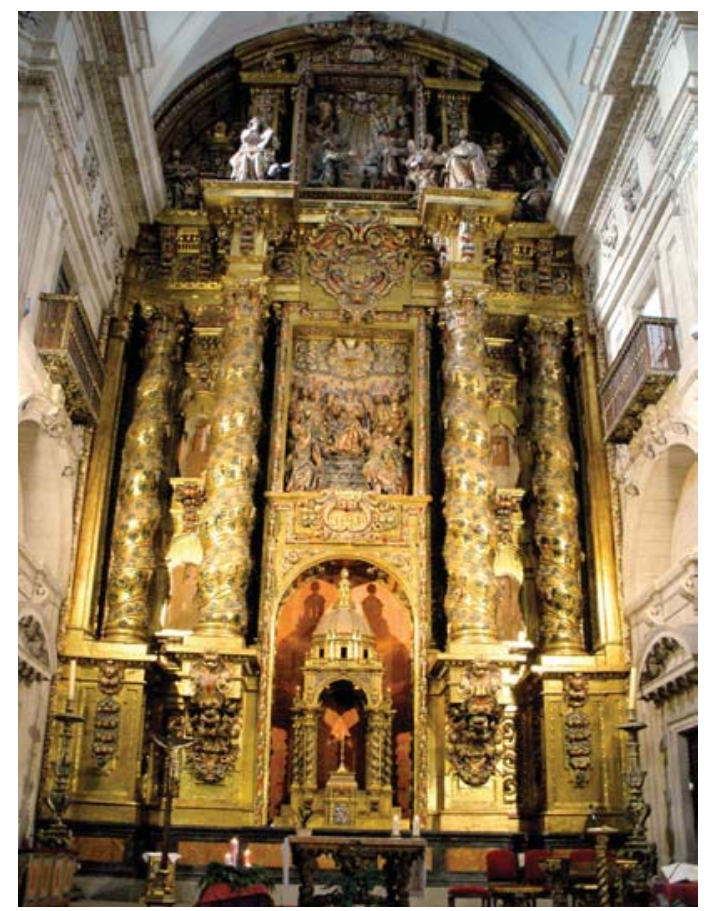

- Fig. 3. Francisco Bautista (traza). Salamanca, colegio de la Clerecía. Retablo mayor. Foto del autor

${ }^{69}$ Archivo Histórico de Protocolos de Madrid, Protocolo 10.125, fol. 102-102 v.

${ }^{70}$ Habla bien a las claras del prestigio de que gozaron Pedro de la Torre y Francisco Bautista por los retablos y tronos que trazaron para patronas de principales ciudades de España, sitas en sus santuarios o catedrales: Vírgenes de Begoña (Bilbao), Fuencisla (Segovia), Sagrario (Toledo), Ojos Grandes (Lugo), y Soterraña (Ávila), además del tabernáculo del patrón de Santiago de Compostela, también de toda España.

${ }^{71}$ Lamentablemente fue sustituido el retablo de Bautista por otro del siglo XVIII. 
La culminación de los retablos de Bautista tuvo lugar en Salamanca, con una obra fundamental, el retablo del colegio real jesuita conocido como la Clerecía (Fig. 3). Hasta ahora se consideraba su tracista a quien lo ensambló, el riosecano Juan Fernández, discípulo de Medina Argüelles. Razones documentales y estilísticas nos llevan a señalar a Bautista como su autor.

Juan Fernández había contratado en Salamanca en febrero de 1673 el retablo colateral del evangelio de la Clerecía, dedicado a San Ignacio, según su traza ${ }^{72}$, y su colaborador Manuel Saldaña en abril el de la epístola, de San Francisco Javier, que seguiría el diseño del otro. Cada uno recibiría 12.000 reales y un taller en el Colegio. Quedaban fuera de su obligación las esculturas, los pedestales de piedra y el dorado, contratado el 5 de septiembre por Antonio Fonseca en 31.000 reales.

La traza para los colaterales se aprobó en Valladolid, sin duda por el padre Jerónimo de Córdoba, provincial de la provincia de Castilla la Vieja por los jesuitas y responsable de la obra por la congregación ahí, pero los vallisoletanos Juan Fernández y Manuel de Saldaña, encargados del ensamblaje y talla, los concertaron en Salamanca y los hicieron allí, en el obrador que se les dio, de modo que los jesuitas salmantinos pudieran controlar el desarrollo de la obra. Hubo cambios respecto a la traza de Juan Fernández, al exigirse esculturas en nichos en vez de pinturas con marcos rectos, y las pirámides en el remate de que se habla en el contrato debieron sustituirse por los jarrones que lucen actualmente. El dorado costó 7.000 reales más que la madera, lo que no parece un signo de excesivo aprecio hacia las dotes de los ensambladores.

Tres semanas después del contrato del dorado, el ya citado Córdoba dio poder

72 Presentada en Valladolid a los jesuitas, pues iba firmada del escribano de esta localidad Gabriel Medina. Quedó en poder del rector de la Clerecía Diego de la Fuente Hurtado. A. RODRÍGUEZ G. DE CEBALLOS, Op. cit., pp. 106-110. en Valladolid a Francisco Marcos de Chaves, procurador general de la orden en Castilla la Vieja, residente en el Colegio Imperial de Madrid, sin duda para disponer la construcción del retablo mayor, lo que incluiría la traza y la elección de maestros. El 24 de diciembre de 1673 concertó Juan Fernández con el padre Córdoba el retablo mayor de talla y ensamblaje. Se indica que la traza estaba hecha y que quedaba firmada por Córdoba, Juan Fernández y el escribano. Conforme a ella se debían tallar y modelar el pedestal principal, los nichos de los intercolumnios y el cuadro con la Pentecostés, pilastras y muros con hojas de espinaca, basas y capiteles y la cornisa principal, y el segundo cuerpo de la vuelta del arco, que incluía los escudos de armas. Basas, sotabasas, cornisas y tímpanos se ensamblarían a la veta para su hermosura y arte. En un timpanillo del cuadro principal sobre la custodia debía tallarse un Jesús como la traza, muy hermoso y con la mejor tarjeta y talla para su mejor adorno. Había aspectos que se especificaron en el contrato por no mostrarse en el diseño, como quince florones que debían guarnecer el fondo de las impostas y arco; también haría florones en los nichos de las historias como pidiese el rector del Colegio aunque no se mostraba en el proyecto, y las seis columnas de la planta debían ser salomónicas. La fábrica se haría en Salamanca en los dos obradores de una casa vieja donde se habían hecho los colaterales. Si algún oficial no gustara podría despedirlo el rector. El maestro comenzaría en Pascua de Resurrección, cuando llegara la madera con el buen tiempo, y a partir de ahí contaría con dos años para acabar, conviniéndose un precio cerrado de 80.000 reales $^{73}$.

En la Clerecía, el orden de los encargos es inverso a lo que era usual, haciéndose antes los colaterales que el retablo mayor. Es posible que con ellos se pusiera a prueba al maestro vallisoletano antes de encomendarle la hechura del mayor. Respecto a la traza de éste, tan solo se dice que quedó firmada por las partes y el escribano, lo que no implica

\footnotetext{
${ }^{73}$ E. GARCÍA CHICO, Documentos..., pp. 340-342.
} 
necesariamente que Fernández fuera su autor, como se ha interpretado. Se le exigió que trabajara en Salamanca, como los colaterales. La escultura se dejó para el prestigioso Juan Rodríguez, el único maestro salmantino del retablo, y para Juan Peti según concierto de 20 de abril de 1674 con el nuevo rector Benito Vázquez. Consistía en los bultos mayores que el natural de los Doctores de la Iglesia y los Evangelistas, y dos grandes relieves de la Pentecostés y la Asunción, y su precio fueron 33.000 reales $^{74}$, muy alto respecto al del ensamblaje y talla.

Agulló dio a conocer sin comentario dos contratos del retablo de la Clerecía que lo relacionan con la Corte ${ }^{75}$. El primero es el concierto de 17 de julio de 1674 en Madrid entre Francisco Marcos de Chaves, por el poder de Córdoba, y Miguel Sombigo y Salcedo, maestro de cantería y marmolista vecino de Madrid, para realizar el pedestal de mármol bajo el retablo. Como fiador aparece su hermano Bartolomé Sombigo y Salcedo, maestro mayor de la catedral de Toledo, aparejador de su Alcázar y ayuda de trazador mayor de las obras reales por poder dado en esa ciudad el 12 de julio de 1674. La obra se había de hacer en Madrid, de mármol de San Pablo y embutidos de jaspe de Cehegín que traerían de estas canteras, y se seguiría la planta, perfil y medida firmada del hermano Francisco Bautista y entregada a Miguel Sombigo. Tenía que estar asentado para fin de marzo de 1675, corriendo por cuenta de la Clerecía los portes del mármol y jaspe desde las canteras a la Corte y el posterior transporte a Salamanca. Recibió de contado 1.500 reales, más 750 reales cada mes desde el 1 de agosto siguiente hasta primero de marzo de 1675. Por cada pie cuadrado superficial me-

${ }^{74}$ J. GONZÁLEZ, “El retablo del altar mayor de la iglesia de la Clerecía de Salamanca", Archivo Español de Arte, 54, 1942, pp. 346-350. 156. dido al asentar se les pagaría 55 reales, descontado lo cobrado previamente ${ }^{76}$.

El segundo contrato es del 7 de julio de 1675. El procurador general concertaba ahora con el dorador y estofador Blas Solano fiado por Juan Antonio Romaña que hipotecaba su casa y José Alonso Toreo, batidores de oro, todos residentes en la Corte, que Solano doraría y estofaría el retablo mayor y su custodia según había acordado con el rector de la Clerecía ${ }^{77}$. El oro debía ser de veinte y tres quilates y tres granos en todo lo visible de custodia y retablo -talla de repisas, marcos tallados, columnas y capiteles, frisos, modillones, florones, tarjetas, festones, enjutas y escudos de armas- y se darían de colores finos imitando al natural ciertas partes, como frutas de los festones o uvas rojas de parra. En vaciados de pilastras, pilastrones y machones, tímpanos de cajas y donde fuera necesario se pintarían subientes de grutescos adornados de niños, aves y mariposas diferentes y otras cosas vivas. También se dorarían túnicas y mantos de los Evangelistas con sus atributos y los Doctores, poniendo color encima que imitara brocados y lamas y con grutescos algunos paños. En los respaldos de los Evangelistas se harían celajes con sus nubes y pedazos de países sobre oro. Del mismo modo se procedería en las figuras de la custodia y en las dos historias del retablo, la Pentecostés y la Asunción, ésta con san Ignacio escribiendo, y en ellas el Espíritu Santo. A estos relieves les pintaría fondos de gloria con resplandores y edificios. En el tablero de respaldo de la custodia iría una gloria de serafines y un pabellón. Se concertó su labor en 105.000 reales, dándole andamios hechos, casa para vivir Solano y sus oficiales solteros y se le socorrería en Salamanca y la Corte con el dinero preciso para el oro, aparejos y demás materiales necesarios, pagando semanalmente el salario de oficiales

\footnotetext{
${ }^{76}$ Fueron testigos los canteros Francisco Martínez y Celedón Gómez, sin duda oficiales de Miguel Sombigo que iban a trabajar en el pedestal.

${ }^{77}$ Se especifica una diferente técnica para la custodia, por ser de nogal.
} 
que estuvieran en Salamanca. Su trabajo se acabaría en un año y medio, desde el 1 de septiembre de 1676 a fin de enero de $1677^{78}$. El precio del dorado, muy alto respecto al del ensamblaje y talla, sólo parece explicable por la extraordinaria calidad de la labor de Solano, que siempre ha sido objeto de grandes alabanzas, y por los mayores precios de los artífices madrileños respecto a los de Valladolid o Salamanca.

Los argumentos a favor de una traza de Bautista son numerosos. En 1647 y 1661, el arquitecto visitó la Clerecía y Rodríguez G. de Ceballos le ha atribuido acertadamente, a raíz del segundo viaje, la modificación de la traza del segundo cuerpo de la fachada del templo ${ }^{79}$, por tener su habitual orden compuesto y cartelas a modo de triglifos. Bautista trazó el pedestal de mármol y jaspe del retablo, lo que es revelador, porque era pequeño y de poca labor, y no tendría sentido que se le llamara a trazar esta parte poco relevante, salvo que hubiera diseñado previamente el retablo ${ }^{80}$. Por otra parte, el recurso a los maestros madrileños Blas Solano -en vez del salmantino Fonseca que doró los colaterales- y los Sombigo, que habían participado en el pedestal del retablo del Colegio Imperial, sugieren que la dirección de la obra se llevaba desde Madrid, donde imponían los artífices, y establecen un vínculo con Bautista. Es razonable pensar, además, que una obra tan fundamental no quedara a la invención y cuidado de Fernández, un ensamblador correcto pero no famoso tracista, teniéndolo tan insigne en la Compañía. El precio de Fernández, además, no justifica sino el pago de una gran estructura de madera con su consiguiente trabajo de ensam-

\footnotetext{
${ }^{78}$ Había recibido ya 500 reales del padre Marcos de Chaves el 26 de junio anterior.

${ }^{79}$ Contratado en 1657 según traza de Mato. A. RODRÍGUEZ G. DE CEBALLOS, Op. cit., p. 79.

${ }^{80}$ No era infrecuente que un ensamblador que hubiera realizado un retablo sobre traza ajena pudiera dibujar luego el pedestal, pero no que un tracista acreditado proyectara solamente el basamento habiendo trazado otro el retablo antes.
}

blaje y talla, pero su comparación con los precios que cobraron los escultores Rodríguez y Peti, o aún más el de Solano, alejan cualquier hipótesis respecto a la traza o a la dirección de la obra.

Igualmente determinantes son los motivos de estilo. Los distintos autores han señalado el parentesco del retablo de la Clerecía con la obra anterior y posterior de Juan Fernández. Entre la anterior a diciembre de 1673 se cuenta el retablo de la parroquial de Pesquera de Duero (1672) y los colaterales de la propia iglesia jesuita de comienzos de 1673. En ellos demuestra, como discípulo de Medina Argüelles ${ }^{81}$, su conocimiento de la obra de Pedro de la Torre en cuanto a las cartelas del banco que abrazan los pedestales, el tipo de tarjetas de la calle central, las pequeñas del zócalo del ático o los jarrones en los extremos de éste. Sin embargo, las calles laterales nos advierten de que se trata de un maestro que no había visto las obras cortesanas del momento, pues los marcos, aunque con codillos, lucen discretas hojas frente a las de mayor tamaño usuales en aquel momento en Madrid y los amplios festones colgantes con frutos y las pequeñas tarjetas que los remontan estaban muy pasados de moda. En Pesquera, además, se observan unos festones en las enjutas en disposición muy poco elegante. Los netos de los bancos están ocupados totalmente por pinturas, desusado a estas alturas en Madrid, donde se prefería la talla. Tras la realización del retablo mayor de la Clerecía, la oportunidad de conocer tan directamente una traza cortesana hizo que adoptara las novedades que contenía en sus retablos posteriores.

En cambio, los rasgos estructurales y decorativos de este retablo coinciden con los de Francisco Bautista en sus retablos y portadas del Colegio Imperial y en el proyecto de retablo utilizado en Azcoitia y Orduña. Así,

\footnotetext{
${ }^{81}$ Además había realizado en 1667 el retablo de San Cebrián de Amayuelas por traza de Cristóbal Ruiz de Andino. Es muy poco bagaje para encargar una obra de tal importancia y tamaño más allá de su ensamblaje y talla.
} 
un pequeño banco con triples roleos superpuestos y grandes cartelas y festones sobre placas recortadas, cuerpo principal mucho mayor que el resto y con columnas gigantes, nichos para esculturas en las entrecalles enmarcados con codillos superiores y tarjetas que acaban en cornisilla, en la parte superior pequeños festones de frutos colgantes de floroncillos, friso con dobles cogollos superpuestos en los lados y tarjetón central sobre piedra del mismo diseño que las portadas del Colegio madrileño; ático pequeño con escudos de los fundadores Felipe III y Margarita de Austria emulando los madrileños de la emperatriz María. Hay también esculturas sedentes y elementos comunes, como machones con fruteros pendientes de cartelas que sostienen un frontón curvo. La imaginería de escultura es adecuada por el descomunal tamaño del retablo. La custodia es muy grande, aunque no ocupa el cuerpo principal como de costumbre, sino parte y todo el banco. La traza tendría los fustes blancos, porque se advirtió a Fernández que debían ser salomónicos, lo que aclara que sean del mismo diseño que los de éste en sus retablos anteriores.

A lo largo de esta sucesión de retablos y otras piezas relacionadas hemos visto cómo el estilo de Pedro de la Torre y Francisco Bautista se propagó desde Madrid por toda Castilla y León, primero de manera leve en obras aisladas de poca repercusión, para eclosionar a partir de los retablos de la Fuencisla y Tordesillas y sus aparejadores, Arroyo y Medina Argüelles y otros maestros de su círculo, en León, Valladolid, Medina de Rioseco o Palencia. El círculo se completa con las trazas del jesuita para los retablos de la Virgen de Soterraña y el magno de la Clerecía salmantina. 